\title{
Determination of Short Chain Fatty Acids in Mice Feces by Capillary Electrophoresis
}

\author{
Letícia A. Marques, ${ }^{a}$ Cinthia B. B. Cazarin, ${ }^{b}$ Juliano Bicas, ${ }^{b}$ Mário R. Maróstica Junior, ${ }^{b}$ \\ Emanuel Carrilho $^{a, c}$ and Stanislau Bogusz, Junior ${ }^{\circledR} *, a$ \\ anstituto de Química de São Carlos (IQSC), Universidade de São Paulo (USP), \\ 13566-590 São Carlos-SP, Brazil \\ ${ }^{b}$ Faculdade de Engenharia de Alimentos (FEA), Universidade Estadual de Campinas (UNICAMP), \\ CP 6154, 13083-970 Campinas-SP, Brazil \\ 'Instituto Nacional de Ciência e Tecnologia de Bioanalítica (INCTBio), \\ CP 6154, 13083-970 Campinas-SP, Brazil
}

\begin{abstract}
Short-chain fatty acids (SCFA) are compounds produced during fermentation of gut microbiota. Acetic, propionic and butyric acids are the most important SCFA produced from non-digestible foods. We developed and validated a rapid and low-cost capillary electrophoretic (CE) method for determination of acetic, propionic and butyric acids in mice feces (100 mg of sample). Electrophoretic separation was performed for SCFA determination in feces samples during $10 \mathrm{~min}$. The method showed good linearity for all analytes (determination coefficient, $\mathrm{r}^{2}>0.98$ ); recovery from 74.1 to $109.8 \%$, while the intra- and interday precision essays were suitable (relative standard deviation $(\mathrm{RSD})<10 \%$ ); and limits of detection and quantification of 0.13-0.43 mM for acetic acid, 0.09-0.29 mM for propionic acid and 0.03-0.09 $\mathrm{mM}$ for butyric acid. Real samples of mice dextran sulfate sodium-induced colitis feces treated with jabuticaba (Plinia cauliflora) aqueous extract were performed successfully.
\end{abstract}

Keywords: short-chain fatty acids, gut fermentation, feces metabolites, method validation

\section{Introduction}

Short-chain fatty acids (SCFA) also called as volatile fatty acids are defined as saturated aliphatic organic compounds containing between 2 to 6 carbon atoms. They are considered as the primary end-products of nondigestible carbohydrate fermentation by the gut microbiota, especially Ruminococcus sp., Bifidobacterium sp., Eubacterium sp. and Clostridium sp. ${ }^{1-5}$ Additionally, a large number of polyphenols from the diet are catabolized by the gut microbiota generating many intermediate and end-products, like phenolic acids and SCFA, with health interesting effects. ${ }^{6}$

SCFA are involved directly or indirectly in many physiologic responses correlated to the immunologic processes, anti-carcinogenic action and cardiovascular diseases risk-reducing. ${ }^{7-9}$ Anti-inflammatory effects of SCFA can be observed due to reducing of signaling of

*e-mail: stanislau@iqsc.usp.br inflammatory pathways, being key gut microbial metabolites associated with inflammatory modulation..$^{10}$ In addition, they can modulate the production of pro-inflammatory molecules by neutrophils and macrophages, as well as increase the release of anti-inflammatory IL-10 cytokine. ${ }^{11}$ Besides that, the SCFAs have a regulatory role in the intestinal environment, and in hepatic and whole-body glucose homeostasis. ${ }^{5,12,13}$

Acetic acid (C2), propionic acid (C3), and butyric acid (C4) are regarded as the most important SCFA to human health. Their abundance is about $95 \%$ of all SCFA produced and the ratio acetate:propionate:butyrate (about 57:22:21) is basically the same at distinct regions of the large intestine. As the most abundant SCFA produced and excreted, acetate is the major product of pectin and xylan degradation and is able to decrease hypercholesterolemia in humans. ${ }^{12,14,15}$ A recent study proved that propionate reduces intrahepatic triglycerides levels, acting as a key compound to liver fat decrease and also visceral fat decrease. ${ }^{16}$ Butyrate is essential in maintaining healthy the colonic epithelium 
because it is the preferred fuel to colonocytes. Butyrate also helps in mucosal proliferation and it is associated with inhibition of colon cancer cell lines. ${ }^{5,17,18}$

To this point, it is remarkable that there is a significant correlation between feeding, gut microbiota, SCFA production and colonic health. ${ }^{19}$ Diets able to improve SCFA production are also beneficial to enteric nervous system (ENS), because these gut-fermentation metabolites influence cell signaling by changing receptors activity, such as toll-like receptor (TLR4) and fatty free acid receptor-2 (FFAR2), cytokines modulation, e.g., interleukin-6 (IL6) and IL-12, tumor necrosis factor $\alpha$ (TNF- $\alpha$ ), nuclear factor kappa $\beta$ (NF- $\kappa \beta)$, and also it affects neurotransmitter levels (for example, mucosal serotonin release). Thus, SCFA are recognized as key signaling molecules to the gut-brain axis. ${ }^{5,20,21}$ Due to its importance to the intestinal mucosa health, some studies have been investigating the production of SCFA in inflammatory bowel disease. Stonerook et al. ${ }^{22}$ observed a decrease in the fecal level of SCFA in cotton-topped tamarins (Saguinus oedipus); these animals when in captivity develops chronic inflammation in large intestine similar to human colitis. Araki et al. ${ }^{23}$ observed a significant reduction in SCFA in fecal samples of Sprague Dawley rats after 7 days dextran sodium sulfate (DSS) induced colitis.

Generally, rodents (mice and rats) are selected by researchers to conduct in vivo studies, because they are small mammalians, present a fast reproduction, and short lifespan, besides having many similar biological processes to human. However, the small size of animals it is a limiting experimental factor once is collected just about 200-300 mg of feces in caecum from each animal after euthanasia. Thus, an analytical methodology for SCFA quantification should use low sample amounts, have sufficient sensibility, low cost, it should be fast, efficient and it should provide reliable results. Capillary electrophoresis (CE) is a separation technique based on the movement of electrically charged particles in a liquid medium when is applied an electric voltage. Comparing with other chromatographic techniques, CE presents some advantages like low cost of analysis, reduced sample and solvent consumption and low band-broadening promoting great peak resolution. ${ }^{24,25}$ Some researchers used CE to quantify SCFA in biological samples, ${ }^{26-28}$ but there is no official method reporting CE use for determination of SCFA from feces of mice.

This research intended to provide a rapid, efficient, easy-handling and low-cost SCFA separation methodology using CE with indirect ultraviolet (UV) detection for determination of acetic, propionic and butyric acids in caecal feces of mice. After validation of the CE UV methodology, we applied to quantify SCFA in mice feces from animals that had induced DSS-colitis and compared to those who received jabuticaba (Plinia cauliflora) aqueous extract. The DSS-colitis model was chosen because some studies ${ }^{29,30}$ have shown the beneficial effects of the consumption of the jabuticaba peel, as well as the intake of its aqueous extract. It is not our objective, however, in this paper to carry out a deep chemical characterization of the composition of the jabuticaba aqueous extract (JAE) or carry out a more detailed study on the biological effects of the consumption of JAE (i.e., tissue antioxidant status, histological evaluation of colon or metabolomics of cecum microbiota). Such study is under way in our group; at this moment, we just have sought to the application of CE UV methodology in the observation of the effects of the peel infusion intake in relation to the SCFA formation in the colitis model.

\section{Experimental}

\section{Chemicals and reagents}

Hydrochloric acid (37.4\%) was purchased from Quimis (Jundiaí, Brazil). Tris(hydroxymethyl)aminomethane (99.8\%) was obtained from Hexapur Bio Lab (Amsterdam, North Holland, Netherlands). Benzoic acid (99.5\%) was obtained from Synth (Diadema, Brazil). Acetic acid (> 99.8\%), propionic acid $(99.8 \%)$ and butyric acid $(>99.5 \%)$ were purchased from Sigma-Aldrich (Schnelldorf, Germany). 2-Ethylbutyric acid (> 99.5\%) was purchased from Chem Service (West Chester, USA). Ultrapure water was obtained from a Millipore ${ }^{\mathrm{TM}}$ system (Simplicity 185, Millipore, Billerica, USA) at a resistivity of $18.2 \mathrm{M} \Omega \mathrm{cm}$, and $\mathrm{pH}$ indicator strips were purchased from Macherey-Nagel (Düren, Germany).

\section{Preparation of stock standard solution}

Acetic, propionic and butyric acid were prepared by dilution of standards in ultrapure water to provide a $400 \mathrm{mmol} \mathrm{L}^{-1}$ stock solution. Internal standard (2-ethylbutyric acid) stock solution was prepared at $10 \mathrm{mmol} \mathrm{L}^{-1}$. Proper volumes of these three analytes were mixed to provide calibration solutions. The internal standard solution (final concentration of $1 \mathrm{mmol} \mathrm{L}^{-1}$ ) was added to all calibration solutions. All solutions were kept refrigerated at $4{ }^{\circ} \mathrm{C}$.

\section{Jabuticaba aqueous extract}

Jabuticaba fruits (Plinia cauliflora) were obtained from a farm in the city of Casa Branca, São Paulo State, 
Brazil (21046'26”'S; 4705'11'W). The fruits were washed, sanitized with hypochlorite solution $200 \mathrm{ppm}$ for $30 \mathrm{~min}$, and rewashed in potable water before use. After the separation of pulp from peels, it was performed the peel drying process at $50{ }^{\circ} \mathrm{C}$ in an oven with air circulating for $48 \mathrm{~h}$. After drying, the samples were ground in a mill (Marconi, São Paulo, Brazil) and stored in a dark bottle under refrigeration. The JAE was prepared using $1.5 \mathrm{~g}$ of dried peel in $100 \mathrm{~mL}$ of boiling water $\left(100^{\circ} \mathrm{C}\right)$ for $15 \mathrm{~min}$. Then, the infusion was filtrated, and it was offered to the animals.

\section{In vivo experimental design}

The present study was approved by the Animal Research and Ethics Committee of the University of Campinas (Brazil) (protocol No. 3594-1/2014) and carried out in accordance with the guideline promoted by the Brazilian College of Animal Experimentation (COBEA).

Female C57BL/6J mice $(15 \pm 1.6 \mathrm{~g})$ were maintained at University of Campinas animal facilities with controlled temperature $\left(22 \pm 2{ }^{\circ} \mathrm{C}\right)$ and light-dark cycle $(12 / 12 \mathrm{~h})$. Mice were randomly assigned as healthy $(\mathrm{n}=6)$, DSS colitic group $(n=10)$, DSS JAE group $(n=10)$. The animals were fed with a commercial diet (Nuvital, Colombo, Brazil) during all the experiment. During fourteen days JAE group received the jabuticaba aqueous extract instead of water ad libitum, as well as, healthy and DSS groups received pure water. Colitis was induced after two weeks substituting the water or JAE by $3 \%(\mathrm{~m} / \mathrm{v})$ DSS aqueous solution. The body weight, the presence of gross blood in the feces, and stool consistency were daily monitored after DSS administration. These parameters were used to establish the disease score according to the criteria proposed by Cooper $e t$ al. ${ }^{31}$ and used to calculate an average daily disease activity index (DAI). After 2 weeks, the animals were sacrificed under anesthesia and cecum content was collected and stored at $-80{ }^{\circ} \mathrm{C}$ until SCFA analysis.

\section{Sample preparation}

Approximately $100 \mathrm{mg}$ of defrosted feces samples were weighed in an analytical balance (model AR2140, Ohaus Corporation, Parsipanny, USA). After, $500 \mu \mathrm{L}$ of ultrapure water was added to each sample and they were vortexed for $3 \mathrm{~min}$. Samples were kept at room temperature for $10 \mathrm{~min}$. Then, the fecal suspension had the $\mathrm{pH}$ adjusted to 2-3 using $50 \mu \mathrm{L}$ of $5 \mathrm{~mol} \mathrm{~L}^{-1}$ hydrochloric acid solution. Samples were centrifuged for $20 \mathrm{~min}$ at $3698 \times \mathrm{g}$ and $4{ }^{\circ} \mathrm{C}$ (model AxySpin R, Axygen, Union City, USA). To $90 \mu \mathrm{L}$ of supernatant from each sample, we added $10 \mu \mathrm{L}$ of
$10 \mathrm{mmol} \mathrm{L}^{-1}$ internal standard (IS) solution (2-ethylbutyric acid). Samples were also diluted 1:10 with background electrolyte (BGE) and injected at capillary electrophoresis system by pressure. Each sample analysis was performed in triplicate.

\section{Separation conditions}

Electrophoretic analyses were carried out using a capillary electrophoresis system model P/ACE ${ }^{\mathrm{TM}} \mathrm{MDQ}$ (Beckman Coulter) using a fused silica capillary of $75 \mu \mathrm{m}$ i.d. $\times 375 \mu \mathrm{m}$ o.d. (Polymicro Technologies, Phoenix, USA) with an effective length of $55 \mathrm{~cm}$ and the total length of $60 \mathrm{~cm}$. Previously to each running, capillary conditioning was executed as described: rinsing with $0.1 \mathrm{~mol} \mathrm{~L}^{-1}$ of sodium hydroxide solution for $2 \mathrm{~min}$; rinsing with ultrapure water for $2 \mathrm{~min}$; rinsing with BGE solution for $2 \mathrm{~min}$. The applied voltage was $+25 \mathrm{kV}$. The hydrodynamic injection was performed for $3 \mathrm{~s}$ by positive pressure application ( $0.5 \mathrm{psi}$; forward). As electrolyte system, it was used $160 \mathrm{mmol} \mathrm{L}^{-1}$ tris(hydroxymethyl)aminomethane: $10 \mathrm{mmol} \mathrm{L}^{-1}$ benzoic acid solution at $\mathrm{pH}$ 8.5. The buffer was filtered using a $0.45 \mu \mathrm{m}$ polyvinylidene difluoride (PVDF) membrane (Captive Syringe, Agilent Technologies, Santa Clara, USA) prior to use. Detection was carried out using ultraviolet (UV) detection at a wavelength of $228 \mathrm{~nm}$, and also a wavelength screening from 200 to $300 \mathrm{~nm}$ as previous studies of Marsili et al. ${ }^{32}$ Zeppa et al. ${ }^{33}$ and de Baere et al..$^{34}$ Quantifications were performed at $228 \mathrm{~nm}$ channel because it has shown a good compromise between sensibility and absence of interferents signal. An adequate separation of the SCFA peaks was achieved within $10 \mathrm{~min}$.

\section{Validation procedure}

For validation purposes of the $\mathrm{CE}$ method for the separation and quantification of SCFA, we followed the regulation RE 899/2003 from National Agency of Sanitary Surveillance (Anvisa), Brazil. ${ }^{35}$ The linearity was assessed in a concentration range of 5 to $30 \mathrm{mmol} \mathrm{L}^{-1}$ to acetic acid; 2 to $10 \mathrm{mmol} \mathrm{L}^{-1}$ to propionic acid, and 1 to $6 \mathrm{mmol} \mathrm{L}^{-1}$ to butyric acid. Each linear range was designed to six different concentrations for the analyte standard solutions. Limits of detection (LOD) and quantification (LOQ) were calculated by three and ten times the ratio of standard deviation of the intercept with the $y$-axis per analytical slope, respectively. The intraday and interday precision were evaluated by relative standard deviation (RSD) of replicate analysis $(n=10$ for intraday and $n=30$ for interday) of standard solution at three concentration levels (low, medium and high) for each analyte (Table 1). 
To estimate accuracy, it was performed a recovery assay $(n=3)$ adding the standard solution to pure feces sample from mice after the extraction step. The same three concentration levels, as used in the precision assay, were employed to evaluate accuracy. The selectivity of the method was investigated using a pool of sample blank, a standard solution of SCFA and IS solution.

\section{Results and Discussion}

\section{Analytical aspects of SCFA separation using CE with indirect} UV detection

In a different way from chromatographic techniques, separation mechanism in CE is based on the mobility of the analytes inside the capillary. When a voltage is applied along to the silica fused capillary, an electric double layer forms and produces the electroosmotic flow (EOF), which is responsible to drive both cations and anions towards the cathode. Therefore, the separation of SCFA depends on their electrophoretic mobility, which is proportional to the charge of the ion and inversely proportional to the molecular mass, shape (diameter) of the molecule. At $\mathrm{pH}$ 8.5, the SCFA are found in anionic form, meaning that the analyte with the lower molecular mass will be the last for eluting from the capillary fused silica column, and then it will present the longest migration time (Tm). Therefore, it was expected and it has been noted the following migration order: EOF marker $(\mathrm{Tm}=3.54 \mathrm{~min})$; 2-ethylbutyric acid $(\mathrm{Tm}=5.93 \mathrm{~min})$; butyric acid $(\mathrm{Tm}=6.74 \mathrm{~min})$; propionic acid $(\mathrm{Tm}=7.54 \mathrm{~min})$, and acetic acid $(\mathrm{Tm}=8.72 \mathrm{~min})$. Figure 1 shows a typical electropherogram observed for a mixture of SCFA standard solutions and internal standard in Milli- $\mathrm{Q}^{\mathrm{TM}}$ purified water. The obtained electropherograms for SCFA analysis were quite clear of interferences, showing up basically signals from the analytes and EOF marker with good resolution. In order to guarantee the identity of the analyzed compounds, ${ }^{36}$ it was performed: (i) single runs for each analytical standard to evaluate migration time (Tm) of the compounds, and also to verify the absence of IS signal; (ii) injections of pure sample extract, sample extract added of IS solution, and sample extract spiked with authentic standards in order to confirm the Tm of the analytes.

The peak symmetry for propionic acid and butyric acid are appropriate. However, an asymmetric shape for acetic acid peak (asymmetry factor $A_{S}=0.203$ ) is noticeable owing to the mismatch of electrophoretic mobility of the analyte and the co-ion of the background electrolyte. This is an example of electrophoretic dispersion phenomenon affecting peak symmetry, causing a fronting at the peak shape since As is lower than 1. Here it is important to highlight that in a different way from chromatography, where there is a parabolic flow performing separation, CE process is ruled by a laminar flow, and so we should not expect a Gaussian peak shape as the same obtained at chromatograms. Thus, it is normal a triangular peak shape for $\mathrm{CE}$ analysis. ${ }^{37}$ Nevertheless, the fronting shape noted for acetic acid peak does not compromise this SCFA analysis once RSD for acetic acid peak areas was lower than 7\%, which showed that this asymmetry does not implicate in poor precision of the measure.

\section{Analytical validation parameters}

This electrophoretic method was validated following Anvisa Resolution No. 899/2003, stated by a Brazilian National Surveillance Regulatory Agency. ${ }^{35}$ For linearity determination, we analyzed six standard solutions diluted sequentially, during three days. To correct procedure execution errors, instrumental variations or matrix interferences, all analyte peak areas were standardized by their corresponding IS peak area in each run. The dynamic range of the method was obtained using standardized analyte areas. The linearity results are presented in Table 2 and it is remarkable that the correlation coefficients $\left(\mathrm{r}^{2}\right)$ are higher than 0.992. Linear range is adequate for analytical work considering typical SCFA concentrations in mice feces samples. Distinct linear range for each analyte were selected due to acetate:propionate:butyrate ratio, as described previously (concentration range of 48-70 $\mathrm{mmol} \mathrm{L}^{-1}$ for acetic acid, $14-20 \mathrm{mmol} \mathrm{L}^{-1}$ to propionic acid and 7-10 $\mathrm{mmol} \mathrm{L}^{-1}$ to butyric acid). ${ }^{8,12}$ Other parameters for linear dynamic range, such as slope (a) and intercept (b), showed appropriated standard deviations.

Table 1. Concentrations of SCFA standard solutions used to perform precision and accuracy

\begin{tabular}{lcccc}
\hline \multirow{2}{*}{ Solution } & \multicolumn{4}{c}{ Analyte concentration / $\mathrm{mM}$} \\
\cline { 2 - 5 } & Acetic acid & Propionic acid & Butyric acid & 2-Ethylbutyric acid \\
\hline Low level (LL) & 5 & 2 & 1 & 1 \\
Medium level (ML) & 15 & 5 & 3 & 1 \\
High level (HL) & 30 & 10 & 6 & 1 \\
\hline
\end{tabular}




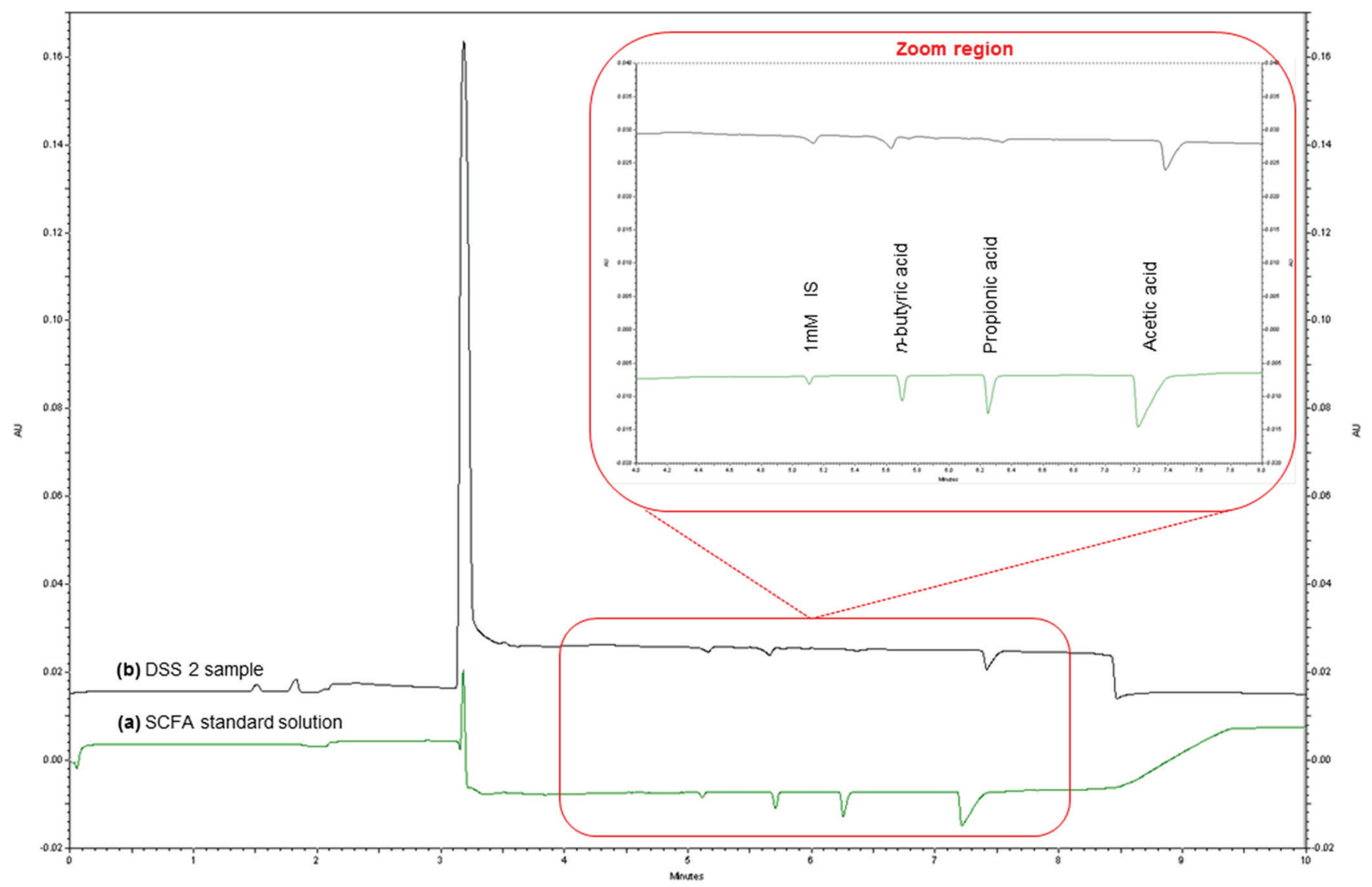

${ }^{*}$ Concentrations: $1 \mathrm{mM}$ IS (2-ethylbutyric acid); $4.0 \mathrm{mM} n$-butiric acid; $6.5 \mathrm{mM}$ propionic acid and 20mM acetic acid.

Figure 1. A typical electropherogram obtained for a mixture of SCFA of (a) standard solution* and (b) for a DSS sample.

Limits of detection and quantification are also presented in Table 2. It is possible to observe that LODs range from 0.026 to $0.128 \mathrm{mmol} \mathrm{L}^{-1}$ and LOQs from 0.087 to $0.0426 \mathrm{mmol} \mathrm{L}^{-1}$. Our work is the first publication that reports SCFA analysis using CE for mice feces. Garcia et al. ${ }^{38}$ carried out SCFA determination in human feces also using an electrophoretic methodology, but those authors used a large amount of feces samples (1 g) if compared of our work (100 mg).
To estimate recovery, $0.1000 \mathrm{~g}$ of mice feces were weighted and carried out sample preparation until the IS addition, as previously described. To the collected supernatant, we added a mixture of SCFA standard solutions in three different levels of concentration (Table S1, Supplementary Information (SI) section). Equal volumes of IS solution was added to each recovery sample (LL, ML, HL) and pure supernatant to contain $1 \mathrm{mmol} \mathrm{L}^{-1}$ of IS. Then, each recovery sample was diluted 1:10 in

Table 2. Validation parameters for SCFA analysis by CE with UV indirect detection

\begin{tabular}{lccc}
\hline \multirow{2}{*}{ Validation parameter } & \multicolumn{3}{c}{ Analyte } \\
\cline { 2 - 4 } & Acetic acid & Propionic acid & Butyric acid \\
\hline Linear range / (mmol L & ) & $2.0 ; 3.5 ; 5.0 ; 6.5 ; 8.0 ; 10$ & $1.0 ; 2.0 ; 3.0 ; 4.0 ; 5.0 ; 6.0$ \\
Slope (a) \pm SD & $1.153 \pm 0.049$ & $1.132 \pm 0.039$ & $1.132 \pm 0.038$ \\
Intercept (b) \pm SD & $2.870 \pm 0.955$ & $-0.172 \pm 0.036$ & $-0.061 \pm 0.010$ \\
$\mathrm{r}^{2}$ & 0.993 & 0.997 & 0.9997 \\
$\mathrm{R}$ & 0.996 & 0.998 & 0.9998 \\
LOD / (mmol L-1) & 0.13 & 0.09 & 0.03 \\
LOQ / (mmol L-1 & 0.43 & 0.29 & 0.09 \\
\hline
\end{tabular}

SD: standard deviation; $\mathrm{r}^{2}$ : determination coefficient; R: correlation coefficient; LOD: limit of detection; LOQ: limit of quantification. 
BGE and analyzed in triplicate. The pure supernatant was added to IS solution to $1 \mathrm{mmol} \mathrm{L}^{-1}$ of final concentration and it was also diluted ten times at BGE. Accuracy results are shown in Table 3. It is outstanding that recovery values ranged from 74.1 to $109.8 \%$, showing a good reliability for the proposed method.

Regarding reproducibility, intraday and interday assays data are presented in Table 4. For the intraday precision assay, we carried out 10 runs per day, and RSD varied between 1.68 to $5.25 \%$. The interday precision was estimated on three different days with a total of 30 analyses, providing RSD values lower than $10 \%$. Then intra- and interday assays results showed an adequate precision for the proposed SCFA electrophoretic separation method.

\section{Method application}

Samples of mice feces $(n=26)$ were successfully analyzed by the described CE method. Each running sample was performed three times. Figure 1 presents an electropherogram for SCFA from mice sample. Considering the typically small amount of sample obtained per animal, the miniaturized sample preparation technique enabled to do at least 2 extractions procedures while separation method can perform at least 10 injections after each sample preparation. This method represents a great possibility to obtain more reliable results with lower RSD values for biological research involving SCFA.

\section{Effects of JAE intake in DSS induced colitis model}

Evidences support that DSS induces colitis due to its toxic effect on the intestinal epithelial cells affecting the integrity of the mucosal barrier, allowing bacterial lumen translocation, promoting infiltration of granulocytes and mononuclear immune cells. ${ }^{39,40}$ The main clinical manifestations are the loss of animal weight, diarrhea and rectal bleeding, which were evaluated for the determination of the DAI (Figure 2).

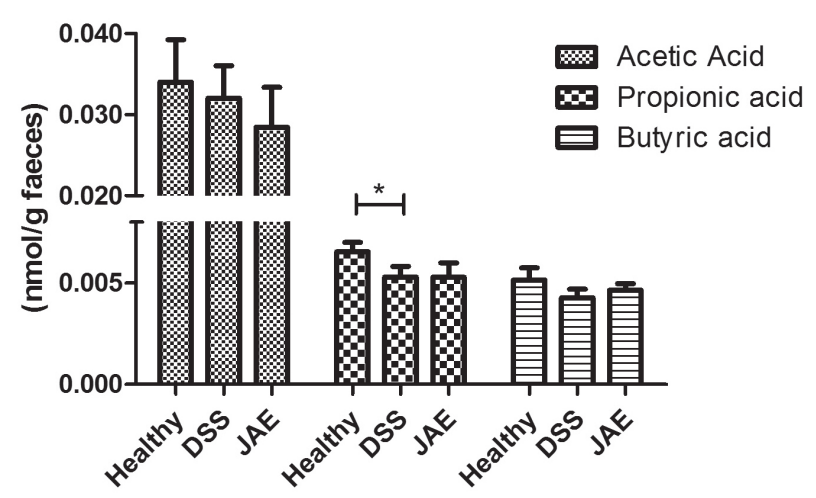

Figure 2. Effects of jabuticaba aqueous extract (JAE) intake in disease activity index (DAI) values of mice. *Indicate significant statistical difference among the groups by the analysis of variance (ANOVA) followed by Tukey's test $(p<0.05)$.

No significant statistical difference was observed in animal weight gains, diet consumption among the groups, as well as in DAI between DSS groups (control $\times$ JAE). The production of SCFA was not affected by JAE intake; however, the production of propionic acid was maintained in the same level compared to the healthy group, differently to the DSS control colitis group that showed a lower level compared to the healthy group (Figure 3). Although, in inflammatory bowel disease the more important SCFA is butyric acid because of its action on intestinal proliferation; the results showed that JAE intake could improve the

Table 3. Average recovery values $(n=3)$ for SCFA separation method in mice feces samples at three different concentration levels

\begin{tabular}{lccc}
\hline \multirow{2}{*}{ Level of concentration } & \multicolumn{3}{c}{ Recovery (average \pm SD) /\% } \\
\cline { 2 - 4 } & Acetic acid & Propionic acid & Butyric acid \\
\hline Low level (LL) & $76.90 \pm 6.60$ & $90.14 \pm 3.36$ & $85.67 \pm 10.20$ \\
Medium level (ML) & $100.1 \pm 8.14$ & $92.72 \pm 2.92$ & $87.88 \pm 8.53$ \\
High level (HL) & $109.8 \pm 13.15$ & $85.87 \pm 5.84$ & $74.07 \pm 6.02$ \\
\hline
\end{tabular}

SD: standard deviation.

Table 4. The intraday and interday precision assay results for SCFA separation method in mice feces samples at three different concentration levels

\begin{tabular}{|c|c|c|c|c|c|c|}
\hline \multirow{2}{*}{ Analyte } & \multicolumn{3}{|c|}{ Intraday assay (RSD) / \% } & \multicolumn{3}{|c|}{ Interday assay (RSD) / \% } \\
\hline & LL & ML & HL & LL & ML & HL \\
\hline Acetic acid & 3.87 & 3.84 & 3.86 & 9.96 & 7.29 & 6.61 \\
\hline Propionic acid & 5.26 & 2.31 & 2.96 & 8.78 & 3.82 & 8.97 \\
\hline Butyric acid & 1.68 & 2.30 & 2.75 & 5.24 & 4.60 & 5.31 \\
\hline
\end{tabular}

RSD: relative standard deviation; LL: low level; ML: medium level; HL: high level. 
formation of propionic acid, which has been associated to health benefits in obesity model, especially because of its ability to decrease cholesterol serum.

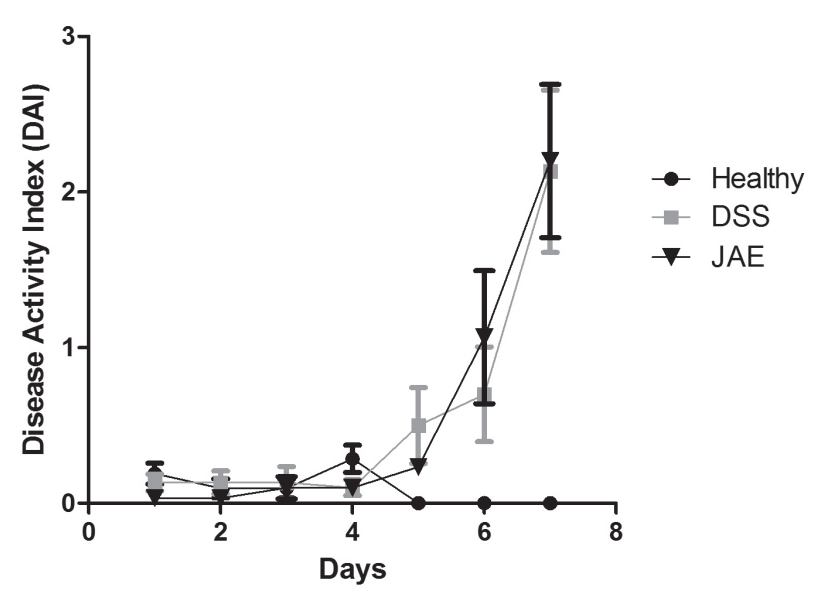

Figure 3. Effects of jabuticaba aqueous extract (JAE) intake in fecal shortchain fatty acids content. Data are expressed as mean \pm standard error of the mean (SEM). It was not verified significant statistical difference among the groups by the analysis of variance (ANOVA) followed by Tukey's test $(p<0.05)$.

\section{Conclusions}

A proper method for SCFA determination was successfully achieved in a short time, with a high resolution. Validation procedure has been shown great linearity, appropriate sensitivity, good accuracy, and reproducibility. Advantages of low sample requirement at sample preparation, as well as in CE injections, allowed accomplishing analysis of SCFA from mice feces samples with better RSD values. Furthermore, CE analysis is cheaper and easier-handling than high performance liquid chromatography, which enables routine uses of this methodology for SCFA quantification.

Regarding the effect of intaking JAE in DSS-colitis model, our results suggest that the consumption of JAE not affected significantly the production of SCFA at the doses experimented here. However, it was observed that the levels of propionic acid in DSS colitis were the same as in the healthy group, suggesting a possible effect.

\section{Supplementary Information}

Supplementary information is available free of charge at http://jbcs.sbq.org.br as PDF file.

\section{Acknowledgments}

The authors thank FAPESP (2015/50333-1), INCTBio (FAPESP 2014/50867-3 and CNPq 465389/2014-7),
CAPES (PROCAD-No. 3007/2014), and CNPq for their financial supporting. M. R. M. J. acknowledges CNPq (301108/2016-1).

\section{References}

1. McNeil, N. I.; Cummings, J. H.; James, W. P.; Gut 1978, 19, 819.

2. Cummings, J. H.; Gut 1981, 22, 763.

3. Macfarlane, G. T.; Gibson, G. R. In Physiological and Clinical Aspects of Short-Chain Fatty Acids Metabolism; Cummings, J. H.; Rombeau, J. L.; Sakata, T., eds.; Cambridge University Press: Cambridge, 1995, ch. 6.

4. Cook, S. I.; Sellin, J. H.; Aliment. Pharmacol. Ther. 1998, 12, 499.

5. Morrison, D. J.; Preston, T.; Gut Microbes 2016, 7, 189.

6. Edwards, C. A.; Havlik, J.; Cong, W.; Mullen, W.; Preston, T.; Morrison, D. J.; Nutr. Bull. 2017, 42, 356.

7. Scheppach, W.; Bartram, H. P.; Richter, F.; Eur. J. Cancer 1995, 31, 1077.

8. Wong, J. M. W.; de Souza, R.; Kendall, C. W. C.; Emam, Z.; David, J. A.; J. Clin. Gastroenterol. 2006, 40, 235.

9. Lattimer, J. M.; Haub, M. D.; Nutrients 2010, 2, 1266.

10. Tedelind, S.; Westberg, F.; Kjerrulf, M.; Vidal, A.; World J. Gastroenterol. 2007, 13, 2826.

11. Vinolo, M. A. R.; Rodrigues, H. G.; Nachbar, R. T.; Curi, R.; Nutrients 2011, 3.

12. den Besten, G.; van Eunen, K.; Groen, A. K.; Venema, K.; Reijngoud, D. J.; Bakker, B. M.; J. Lipid Res. 2013, 54, 2325.

13. Ohira, H.; Tsutsui, W.; Fujioka, Y.; J. Atheroscler. Thromb. 2017, 24, 660 .

14. Macfarlane, S.; Macfarlane, G. T.; Proc. Nutr. Soc. 2003, 62, 67.

15. Hijova, E.; Chmelarova, A.; Bratisl. Lek. Listy 2007, 108, 354.

16. Chambers, E. S.; Viardot, A.; Psichas, A.; Morrison, D. J.; Murphy, K. G.; Zac-Varghese, S. E. K.; MacDougall, K.; Preston, T.; Tedford, C.; Finlayson, G. S.; Blundell, J. E.; Bell, J. D.; Thomas, E. L.; Mt-Isa, S.; Ashby, D.; Gibson, G. R.; Kolida, S.; Dhillo, W. S.; Bloom, S. R.; Morley, W.; Clegg, S.; Frost, G.; Gut 2015, 64, 1744.

17. Hinnebusch, B. F.; Meng, S.; Wu, J. T.; Archer, S. Y.; Hodin, R. A.; Nutr. Cancer 2002, 132, 1012.

18. Thibault, R.; Blachier, F.; Darcy-Vrillon, B.; de Coppet, P.; Bourreille, A.; Segain, J. P.; Inflammatory Bowel Dis. 2010, 16,684 .

19. Topping, D. L.; Clifton, P. M.; Physiol. Rev. 2001, 81, 1031.

20. Carabotti, M.; Scirocco, A.; Maselli, M. A.; Severi, C.; Ann. Gastroenterol. 2015 28, 203.

21. Mayer, E. A.; Tillisch, K.; Gupta, A.; J. Clin. Invest. 2015, 125, 926. 
22. Stonerook, M. J.; Tefend, K. S.; Sharma, H. M.; Peck, O. C.; Wood, J. D.; Dig. Dis. Sci. 1996, 41, 161.

23. Araki, Y.; Andoh, A.; Tsujikawa, T.; Fujiyama, Y.; Bamba, T.; Eur. J. Gastroenterol. Hepatol. 2001, 13, 107.

24. Monnig, C. A.; Kennedy, R. T.; Anal. Chem. 1994, 66, 280.

25. Altria, K. D. In Handbook of Capillary Electrophoresis, $2^{\text {nd }}$ ed.; Landers, J., ed.; CRC Press: Boca Raton, 1996, ch. 7.

26. Zuriguel, V.; Caussé, E.; Bounéry, J. D.; Nouadje, G.; Siméon, N.; Nertz, M.; Salvayre, R.; Couderc, F.; J. Chromatogr. A 1997, 781,233

27. Arellano, M.; Jomard, P.; el Kaddouri, S.; Roques, C.; Nepveu, F.; Couderc, F.; J. Chromatogr. B: Biomed. Sci. Appl. 2000, 741, 89.

28. Primec, M.; Mičetić-Turk, D.; Langerholc, T.; Anal. Biochem. 2017, 526, 9.

29. Leite-Legatti, A. V.; Batista, A. G.; Dragano, N. R. V.; Marques, A. C.; Malta, L. G.; Riccio, M. F.; Food Res. Int. 2012, 49, 596.

30. Plaza, M.; Batista, A. G.; Cazarin, C. B.; Sandahl, M.; Turner, C.; Ostman, E.; Food Chem. 2016, 211, 185.

31. Cooper, H. S.; Murthy, S. N.; Shah, R. S.; Sedergran, D. J.; Lab. Invest. 1993, 69, 238.
32. Marsili, R. T.; Ostapenko, H.; Simmons, R. E.; Green, D. E.; J. Food Sci. 1981, 46, 52.

33. Zeppa, G.; Conterno, L.; Gerbi, V.; J. Agric. Food Chem. 2001, 49, 2722.

34. de Baere, S.; Eeckhaut, V.; Steppe, M.; de Maesschalck, C.; de Backer, P.; van Immerseel, F.; Croubels, S.; J. Pharm. Biomed. Anal. 2013, 80, 107.

35. Agência Nacional de Vigilância Sanitária (ANVISA); Resolução RE No. 899, 29/05/2003, DOU No. 104, 02/06/2003, available at http://portal.anvisa.gov.br/documents/10181/2718376/ RE_899_2003_COMP.pdf/ff6fdc6b-3ad1-4d0f-9af23625422e6f4b, accessed in February 2019.

36. Lu, B.; Westerlund, D.; Electrophoresis 1998, 19, 1683.

37. Jorgenson, J. W.; Lukacs, K. D.; Science 1983, 222, 266.

38. Garcia, A.; Olmo, B.; Lopez-Gonzalvez, A.; Cornejo, L.; Rupérez, F. J.; Barbas, C.; J. Pharm. Biomed. Anal. 2008, 46, 356.

39. Ni, J.; Chen, S. F.; Hollander, D.; Gut 1996, 39, 234.

40. Perše, M.; Cerar, A.; J. Biomed. Biotechnol. 2012, 13.

Submitted: October 16, 2018 Published online: February 21, 2019 